\title{
Evaluation of Male Sexual Dysfunction Associated with Laparoscopic versus Open Resection in Rectal Cancer in Different Age Groups
}

\author{
Haytham Gareer, Waheed Yousry Gareer, Alaadin Hussien* \\ Surgical Oncology Department, National Cancer Institute (NCI), Cairo University, Cairo, Egypt \\ Email: *alaadin.osman@yahoo.com
}

How to cite this paper: Gareer, H., Gareer, W.Y. and Hussien, A. (2019) Evaluation of Male Sexual Dysfunction Associated with Laparoscopic versus Open Resection in Rectal Cancer in Different Age Groups. Journal of Cancer Therapy, 10, 727-738. https://doi.org/10.4236/jct.2019.109061

Received: August 12, 2019

Accepted: September 6, 2019

Published: September 9, 2019

Copyright () 2019 by author(s) and Scientific Research Publishing Inc. This work is licensed under the Creative Commons Attribution International License (CC BY 4.0).

http://creativecommons.org/licenses/by/4.0/ (c) (i) Open Access

\begin{abstract}
Background and goals Sexual dysfunction is a well-documented complication of rectal cancer surgery, with a reported incidence of $18 \%-59 \%$. The objective of this study is to evaluate the incidence of sexual dysfunction (SD) in males after radical resection for rectal cancer and to compare the outcome of open versus laparoscopic rectal resection for different age groups. Patients and methods This prospective randomized study assessed outcomes in male patients that underwent rectal resection for rectal cancer from January 2012 until March 2015 at two large tertiary hospitals in Cairo, Egypt. The patients were randomly allocated into two groups (laparoscopic and open technique) of 40 patients each using the odd number policy for patient allocation. Patients included in each group were further subdivided into two groups according to the type of rectal resection either anterior resection (AR) or abdominoperineal resection (APR). Erectile function was evaluated preoperatively and postoperatively at 3 and 6 months using the International Index of Erectile Function (IIEF) questionnaire. Results There was no significant difference between the laparoscopic and open total mesorectal excision (TME) groups when comparing IIEF score preoperatively. At 3 months postoperatively, the laparoscopic arm showed better results over the open arm (abnormal IIEF in $57.5 \%$ vs. $67.5 \%$ ). The study demonstrated dramatic improvement in SD in both groups at 6 months postoperatively (abnormal IIEF score of $40 \%$ in the laparoscopic vs. $42.5 \%$ in the open arm) with no significant difference in IIEF score between the two groups (p-value 0.876). At 3 and 6 months postoperatively, younger patients showed significant improvement in SD compared to older patients in both groups with more significant improvement in the laparoscopic group (16.7\% vs. $40 \%)$. Patients with APR show more SD compared with AR patients whether laparoscopic or open as
\end{abstract}


seen by the abnormal IIEF scores for the the two groups [the laparoscopic group APR patients showed $62.5 \%$ abnormal IIEF at 3 months that decreased to $50 \%$ after 6 months compared to $56.3 \%$ and $37.5 \%$ at 3 and 6 months respectively for lap. AR patients, and in the open group APR patients also showed higher abnormal IIEF of $71.4 \%$ and improved to $42.9 \%$ at 3 and 6 months respectively compared to $66.7 \%$ and $42.3 \%$ at 3 and 6 months respectively for open AR), which shows that APR whether laparoscopic or open causes more sexual dysfunction than AR. Conclusion In this randomized prospective study, there was no significant difference between the laparoscopic and open TME when we compared IIEF scores. In patients younger than 30 years, the significant improvement in the laparoscopic arm adds to the favorable outcome of laparoscopic TME as regards postoperative complications, postoperative pain, hospital stay, the return of bowel functions and cosmetic results.

\section{Keywords}

Rectal Cancer, Laparoscopic TME, Open TME, Male Sexual Dysfunction

\section{Introduction}

Colorectal cancer is the sixth most common malignancy in Egypt after breast, liver, urinary bladder, Non-Hodgkin's Lymphoma, and lung cancer, accounting for $6.3 \%$ and $4.3 \%$ of male and female cancers respectively. It is reported at a relatively young age, starting at early adolescence with an incidence of $0.2 / 100,000$ males in the age group 15 - 19 years. The highest rates were reported in patients over 40 years, specifically within the age group of 50 - 54 years [1]. Other studies from Egypt have reported a high incidence (35\%) of colorectal cancer occurring in patients younger than 40 years, which is five times higher than the average incidence throughout the world [2] [3]. The high incidence, in this very young patient population, reflects the importance of the sexual function preservation while managing colorectal cancer.

Sexual dysfunction is a well-documented complication of rectal cancer surgery. The reported incidence is $18 \%$ - 59\%, which can significantly influence the quality of life (QoL). Total Mesorectal Excision (TME), introduced by Heald in 1982 [4], has been reported to decrease the incidence of the urinary bladder and sexual dysfunction [5]. The primary principles of TME, whether laparoscopic or open, are to achieve oncologic clearance of the tumor and improve overall disease-free survival [6]. In addition, bladder and sexual function are important aspects in QoL assessment after resection of rectal cancer.

The objective of this study is to evaluate the incidence of sexual dysfunction in males after radical resection of rectal cancer and to compare open versus laparoscopic rectal resection results on sexual dysfunction for different age groups at 3 and 6 months postoperatively. 


\section{Patients and Methods}

This prospective randomized study included 80 male patients that underwent rectal resection either Anterior Resection (AR) or Abdominoperineal Resection (APR) for confirmed rectal adenocarcinoma in the period from January 2012 until March 2015. The study was conducted at the National Cancer Institute, Cairo University, and the Police Hospital, both in Cairo, Egypt.

Selection criteria included all pathologically proven non-metastatic rectal cancer patients presented to us in this time period (JAN. 2012-March 2015) in both mentioned hospitals who were found to be fit for surgery after performing full lab assessment and anesthesia consultation

The consented patients were randomly allocated into one of two groups, "laparoscopic" or "open", with 40 patients each, using the odd number policy for patient allocation. Patients included in each group were further divided into two subgroups according to the type of rectal resection either AR or APR.

For all patients, preoperative assessment including clinical, laboratory, colonoscopy with biopsy, and CT. Patients with stage T3 or T4 disease, without distant metastasis, were treated with preoperative neo-adjuvant chemo-radiation ( 45 Gy over 4 weeks) and re-evaluated 4 weeks after the end of the treatment by clinical examination and MRI. Surgery was performed 6 - 8 weeks after completion of neoadjuvant treatment.

Erectile function was evaluated preoperatively for all 80 patients using the International Index of Erectile Function (IIEF) questionnaire, which is a 15 item validated instrument designed to measure the sexual function of men [7]. The 15 items checked include erectile frequency, erection firmness, penetration ability, maintenance frequency, maintenance ability, intercourse frequency, intercourse satisfaction, intercourse enjoyment, ejaculation frequency, orgasm frequency, desire frequency, desire level, overall satisfaction, relation satisfaction, and erection evidence. Based on these 15-item analyses, five response domains were identified: erectile function, orgasm function, sexual desire, intercourse satisfaction and overall satisfaction, with a range between 5 and 75 points.

The questionnaire was given once preoperatively (Baseline level), then at 3 and 6 months postoperatively. The measured outcome of the study represented the patient's sexual function, as indicated by the IIEF total score, as well as by the incidence of sexual dysfunction derived by the proportion of patients with abnormal IIEF scores, where a total score less than 42.9 is considered abnormal, as designated by Rosen and his colleagues [7].

All data from this study were collected prospectively. Descriptive statistics (mean $\pm \mathrm{SD}$, and $95 \% \mathrm{CI}$ ) were used to summarize patient demographics and operation results. Continuous variables were compared by use of Student's $t$ test and categorical values with Fisher's exact test. All data were subjected to linear regression and correlation where applicable. Significant level was accepted at probability below $5 \%$. All statistical calculations were done using computer programs Microsoft Excel version 7 and Statistical Package for Social Science (SPSS 
Inc., Chicago, IL, USA) statistical program.

\section{Results}

The study included 80 patients, randomly allocated into two equal groups (Laparoscopic vs. Open) of 40 patients. In group I (Laparoscopic), patients underwent laparoscopic total mesorectal excision (LTME), among whom 32 patients undergoing a laparoscopic anterior resection (LAR) and 8 patients undergone a laparoscopic abdominoperineal resection (LAPR). While in group II (Open), patients had open total mesorectal excision (OTME), among whom 33 patients have undergone an open anterior resection (OAR) and 7 patients have undergone an open abdominoperineal resection (OAPR). Patient and tumor characteristics demonstrate no statistical difference detected between the two groups (Table 1).

The preoperative baseline scores of IIEF and postoperative scores at 3 and 6 months for both groups are demonstrated in (Table 2). The mean base line score for LTME and OTME showed no statistical difference $(\mathrm{p}=0.966)$. Analysis of postoperative score at 3 months showed favorable results for LTME group with an abnormal score in $57.5 \%$ compared to $67.5 \%$ for the OTME group, reflecting more early improvement in the LTME group with no statistical significance. The mean IIEF score was also higher for the LTME group (42.25) versus (36.11) for the OTME group with no statistical difference $(\mathrm{p}=0.494)$. At 6 months postoperatively, abnormal scores were reported in $40 \%$ of patients in the LTME group compared to $42.5 \%$ in the OTME group reflecting more late improvement in the OTME group with no statistical difference $(\mathrm{p}=0.879)$.

The preoperative and postoperative scores of IIEF at 3 and 6 months according to age group results are in Table 3. Patients classified into three groups: $<30$ years, 31 - 59 years and $>60$ years. The difference in sexual dysfunction and mean IIEF score in the three age groups were statistically significant in favor of the young group $(\mathrm{p}<0.0421)$.

As seen in this (Table 3 ), older patients $>60$ years show higher abnormal IIEF scores $(71.4 \%$ at 3 and 6 month for laparoscopic group and much higher for open group $89.9 \%$ and $77.8 \%$ at 3 and 6 month respectively) but younger patients $<30$ years show the best scores (with abnormal IIEF scores of $33.7 \%$ and $16.7 \%$ in the laparoscopic group at 3 and 6 months repectively and $40 \%$ for the open group at both 3 and 6 months).

Comparing the type of surgery whether AR Vs APR we found that in the laparoscopic group (62.5\% showed abnormal IIEF at 3 months and decreased to $50 \%$ after 6 months compared to $56.3 \%$ and $37.5 \%$ at 3 and 6 months respectively for lap. AR patients), and in the open group APR patients also showed higher abnormal IIEF of $71.4 \%$ and improved to $42.9 \%$ at 3 and 6 months respectively compared to $66.7 \%$ and $42.3 \%$ at 3 and 6 months respectively for open $A R$ ), which shows that APR whether laparoscopic or open causes more sexual dysfunction than AR. 
Table 1. Patients and tumor Characteristics.

\begin{tabular}{lccc}
\hline & $\begin{array}{c}\text { Laparoscopic Group } \\
(\mathbf{n}=40)\end{array}$ & $\begin{array}{c}\text { Open Group } \\
(\mathbf{n}=40)\end{array}$ & P value \\
\hline $\begin{array}{l}\text { Age range } \\
\text { Mean age }\end{array}$ & $19-64$ & $23-69$ & \\
Age stratification & $54 \pm 8.3$ & $55 \pm 6.45$ & \\
- Under 30 years & 6 & 5 & 0.853 \\
- years 31 - 59 years & 27 & 26 & \\
- Over 60 years & 7 & 9 & \\
Type of resection: $\mathbf{n}(\%)$ & & & \\
- Anterior Resection & $32(80.0)$ & $33(82.5)$ & 0.9617 \\
- APR & $8(20.0)$ & $7(17.5)$ & 0.8775 \\
Tumor stage: $\mathbf{n}$ (\%) & & & \\
- pT1, pT2 & $22(55.0)$ & $19(47.5)$ & 0.8075 \\
- pT3, pT4 & $18(45.0)$ & $21(52.5)$ & 0.8661 \\
Nodal stage: $\mathbf{n}$ (\%) & & & \\
- pN0 & $25(62.5)$ & $23(57.5)$ & 0.9135 \\
- pN+ & $15(37.5)$ & $17(42.5)$ & 0.8035 \\
Neo-adjuvant RT: $\mathbf{n}$ (\%) & & & \\
- Yes & $18(45.0)$ & $21(52.5)$ & 0.682 \\
- No & $22(55.0)$ & $19(47.5)$ & 0.775 \\
Adjuvant CT: $\mathbf{n}$ (\%) & & & \\
- Yes & $14(35.0)$ & $23(57.5)$ & 0.835 \\
- No & $26(65.0)$ & & 0.797 \\
\hline
\end{tabular}

APR: Abdomino-Perineal Resection; pT: pathologic Tumor stage; pN: pathologic lymph node stage; RT: Radiotherapy; CT: Chemotherapy.

Table 2. Preoperative base line scores of IIEF and postoperative scores at 3 and 6 months for both groups.

\begin{tabular}{|c|c|c|c|c|c|c|c|}
\hline \multirow[t]{2}{*}{ Scores of IIEF } & \multicolumn{3}{|c|}{ Laparoscopic Group } & \multicolumn{3}{|c|}{ Open Group } & \multirow{2}{*}{$\begin{array}{l}\begin{array}{l}\text { Grand } \\
\text { Total }\end{array} \\
\text { n (\%) } \\
80(100.0)\end{array}$} \\
\hline & $\begin{array}{l}\text { AR } \\
\mathrm{n}=32 \\
\mathrm{n}(\%)\end{array}$ & $\begin{array}{l}\text { APR } \\
\mathrm{n}=8 \\
\mathrm{n}(\%)\end{array}$ & $\begin{array}{l}\text { Total } \\
\text { n (\%) } \\
40(100.0)\end{array}$ & $\begin{array}{l}\mathrm{AR} \\
\mathrm{n}=33 \\
\mathrm{n}(\%)\end{array}$ & $\begin{array}{l}\text { APR } \\
n=7 \\
n(\%)\end{array}$ & $\begin{array}{l}\text { Total } \\
\mathrm{n}(\%) \\
40(100.0)\end{array}$ & \\
\hline \multicolumn{8}{|l|}{ Baseline scores: } \\
\hline - Normal & $26(81.1)$ & $7(87.5)$ & $33(82.5)$ & $2678.8)$ & $5(71.4)$ & $31(77.5)$ & $64(80.0)$ \\
\hline - Abnormal & $6(18.9)$ & $1(12.5)$ & $7(17.5)$ & $7(22.2)$ & $2(28.6)$ & $9(22.5)$ & $16(20.0)$ \\
\hline - Mean IIEF & 55.20 & & & 54.20 & & & 57.175 \\
\hline - $P$ value & & & & & & & 0.966 \\
\hline \multicolumn{8}{|c|}{ Postop. (3 months) } \\
\hline - Normal & $14(43.7)$ & $3(37.5)$ & $17(42.5)$ & $11(33.3)$ & $2(28.6)$ & $13(32.5)$ & $30(37.5)$ \\
\hline - Abnormal & $18(56.3)$ & $5(62.5)$ & $23(57.5)$ & $22(66.7)$ & $5(71.4)$ & $27(67.5)$ & $50(62.5)$ \\
\hline - Mean IIEF & 42.25 & & & 36.11 & & & 40.68 \\
\hline - $P$ value & & & & & & & 0.494 \\
\hline \multicolumn{8}{|c|}{ Postop. (6 months) } \\
\hline - Normal & $20(62.5)$ & $4(50.0)$ & $24(60.0)$ & $19(57.6)$ & $4(57.1)$ & $23(57.5)$ & $47(58.8)$ \\
\hline - Abnormal & $12(37.5)$ & $4(50.0)$ & $16(40.0)$ & $14(42.3)$ & $3(42.9)$ & $17(42.5)$ & $33(41.2)$ \\
\hline - Mean IIEF & 44.90 & & & 43.29 & & & 44.1 \\
\hline - $P$ value & & & & & & & 0.876 \\
\hline
\end{tabular}

IIEF: International Index of Erectile Function; AR: Anterior Resection; APR: Abdomino-Perineal Resection; Postop.: Postoperative. 
Table 3. Preoperative base line scores of IIEF and postoperative score at 3 and 6 months for both groups according to age.

\begin{tabular}{|c|c|c|c|c|c|c|c|c|}
\hline \multirow{3}{*}{ Scores of IIEF } & \multicolumn{4}{|c|}{ Laparoscopic Group } & \multicolumn{4}{|c|}{ Open Group } \\
\hline & $\begin{array}{l}\leq 30 \\
\mathrm{n}(\%)\end{array}$ & $\begin{array}{l}31-60 \\
\text { n (\%) }\end{array}$ & $\begin{array}{l}\geq 61 \\
\mathrm{n}(\%)\end{array}$ & $\begin{array}{l}\text { Total } \\
\text { n (\%) }\end{array}$ & $\begin{array}{l}<30 \\
\mathrm{n}(\%)\end{array}$ & $\begin{array}{l}31-59 \\
\text { n (\%) }\end{array}$ & $\begin{array}{l}>60 \\
\mathrm{n}(\%)\end{array}$ & $\begin{array}{l}\text { Total } \\
\text { n (\%) }\end{array}$ \\
\hline & $6(15.0)$ & $27(67.5)$ & $7(17.5)$ & $40(100.0)$ & $5(12.5)$ & $26(65.0)$ & $9(27.5)$ & $40(100.0)$ \\
\hline \multicolumn{9}{|l|}{ Baseline scores: } \\
\hline - Normal & $6(100.0)$ & $23(85.2)$ & $4(57.1)$ & $33(82.2)$ & $4(80.0)$ & $22(84.6)$ & $5(55.5)$ & $31(77.5)$ \\
\hline - Abnormal & $0(0.0)$ & $4(14.8)$ & $3(46.9)$ & $7(17.5)$ & $1(20.0)$ & $4(17.4)$ & $4(44.5)$ & $9(22.5)$ \\
\hline - Mean IIEF & 64.9 & 54.2 & 46.6 & 54.47 & 61.7 & 56.3 & 44.6 & 54.18 \\
\hline - $P$ value & & & & $<0.0327$ & & & & $<0.0274$ \\
\hline \multicolumn{9}{|l|}{$\begin{array}{l}\text { Postop. } \\
\text { (3 months) }\end{array}$} \\
\hline - Normal & $4(66.7)$ & $11(40.7)$ & $2(28.6)$ & $17(42.5)$ & $3(60.0)$ & $9(40.9)$ & $1(11.1)$ & $13(32.5)$ \\
\hline - Abnormal & $2(33.7)$ & $16(59.3)$ & $5(71.4)$ & $23(57.5)$ & $2(40.0)$ & $17(59.1)$ & $8(89.9)$ & $27(67.5)$ \\
\hline - Mean IIEF & 52.1 & 38.4 & 33.5 & 39.58 & 48.6 & 35.3 & 28.8 & 35.5 \\
\hline - $P$ value & & & & $<0.0421$ & & & & $<0.0388$ \\
\hline \multicolumn{9}{|l|}{$\begin{array}{l}\text { Postop. } \\
\text { ( } 6 \text { months) }\end{array}$} \\
\hline - Normal & $5(83.3)$ & $17(63.0)$ & $2(28.6)$ & $24(60.0)$ & $3(60.0)$ & $18(68.2)$ & $2(22.2)$ & $23(57.5)$ \\
\hline - Abnormal & $1(16.7)$ & $10(37.0)$ & $5(71.4)$ & $16(40.0)$ & $2(40.0)$ & $8(41.8)$ & $7(77.8)$ & $17(42.5)$ \\
\hline - Mean IIEF & 57.1 & 46.6 & 34.2 & 45.52 & 52.82 & 43.38 & 31.67 & 40.35 \\
\hline - P value & & & & $<0.0334$ & & & & $>0.0350$ \\
\hline
\end{tabular}

IIEF: International Index of Erectile Function; AR: Anterior Resection; APR: Abdomino-Perineal Resection; Postop.: Postoperative.

\section{Discussion}

Normal sexual functions are controlled by sympathetic input from the superior hypogastric plexus and parasympathetic input from the pelvic splanchnic nerves. Injury to sympathetic supply can result in ejaculatory difficulties, whereas injury to parasympathetic supply results in erectile dysfunction [8].

Sexual dysfunction occurs in about $10 \%-80 \%$ of men after surgery for rectal cancer [8] [9] [10]. The incidence is particularly high in APR since damage to the nerves is difficult to avoid in this case due to the proximity of the nerves supplying the corpora cavernosa. This has been recognized as a risk factor in several studies [11] [12] [13]. Laparoscopic surgery, though technically demanding, has the advantage of clear visualization of the autonomic nerves, an advantage that could facilitate the identification and the preservation of these nerves [14].

Advanced tumors, prior surgery in the pelvis [14] [15] and age $>60$ years [16] have been described as additional risk factors for sexual dysfunction after TME. In contrast to voiding dysfunction, sexual dysfunction is usually permanent. Similar to the voiding dysfunction, the rate of sexual dysfunction can be clearly reduced to $5 \%$ and $33 \%$, if the autonomic nerves are identified and preserved [15] [17] [18] [19]. The pelvic nerves, located very close to the mesorectum, may be injured during mesorectal resection. Therefore, direct visualization and accurate dissection during TME are crucial for pelvic nerve preservation [20] [21]. 
The pelvic parasympathetic nerves may be damaged at a number of points during rectal surgery. Neuropraxia or even avulsion of sacral roots 2, 3 and 4, may result from excessive traction on the rectum during posterior mobilization. The pelvic plexus, itself, is most at risk during lateral dissection at the level of the middle hemorrhoidal vessels. In APR, the neural injury may also occur during the perineal phase, since the nerves are visible after the division of recto-urethralis muscle, making them highly vulnerable [19].

In this study, the mean age in the laparoscopic and open group was 54 and 55 respectively which is younger than that reported in western series due to the early occurrence of rectal cancer in Egypt. Soliman and colleagues [3], reported that $16.6 \%$ of Egyptian colorectal cancer patients are below the age of 30 years which is also supported by other studies [20] [21]. In western countries, patients younger than 30 years represent $0.47 \%$ of rectal cancers in Canada [22], $1.5 \%$ in the USA [23] and 3\% in France [24]. This younger age at presentation may be responsible for the high mean baseline IIEF scores reported in our patients in both groups (58.75 and 55.6 respectively). The overall pre operative abnormal IIEF in our patients was $20 \%$ with no statistical difference between the two groups $(17.5 \%$ vs. $22.5 \%$ for the laparoscopic and open group, respectively ( $\mathrm{p}$ value $=0.966)$. The overall pre operative low Incidence of abnormal IIEF in our study is likely related to the younger mean age at presentation (54 years). In a detailed retrospective study, the mean IIEF score was 29.3 and it was found that $43 \%$ of sexually active men and $69 \%$ of overall men had IIEF scores considered abnormal [25].

The result with respect to postoperative sexual functioning varies widely between surgeons and institutions. The CLASSIC (Conventional vs. Laparoscopic-Assisted Surgery In Colorectal Cancer) trial was the first RCT to include patients with rectal cancer [26]. The CLASSIC trial, as well as other studies, demonstrated laparoscopic rectal resection is associated with increased risk of both sexual and urinary dysfunction, with $41 \%$ of men in the laparoscopic rectal surgery group had sexual dysfunction following laparoscopic anterior resection, compared to $23 \%$ in the open group [27] [28]. Analyzing prospectively collected data of the CLASSIC study, alongside a single time point assessment, Jayne and his colleagues [29], found no significant difference in the domain-specific scores between the two groups, however, the overall sexual functions tended to be worse after laparoscopic than after open rectal surgery. Nevertheless, the outcomes of the MRC CLASICC trial should be interpreted with caution, since the study design had set the surgeons' learning curve at only 20 laparoscopic resections. This cut-off point was based on the best available data at that time, which was an underestimation of the learning curve needed for laparoscopic rectal surgery (LRS) [30].

In the Colorectal Cancer Laparoscopic or Open Resection (COLOR II) trial, comparing laparoscopic and open surgery for rectal cancer, thirty-eight questions covered four functional scales/single items (body image, sexual function- 
ing, sexual enjoyment, future perspective) and eight symptom scales/items (micturition problems, chemotherapy side-effects, gastrointestinal symptoms, male sexual problems, female sexual problems, defecation problems, stoma-related problems and weight loss). No differences were detected between groups in data, at any point of time measured. Future perspective scores improved over time in both groups, with no difference between the two surgical techniques [31].

The principal finding in this study was the high rates of sexual dysfunction at 3 months postoperatively, which was $57.5 \%$ and $67.5 \%$ for the laparoscopic and the open group, respectively, with no statistical difference. This was similar to the findings of a study that found a dramatic decrease in IIEF scores postoperatively, and high rates of SD which exceeded $60 \%$ at 3 and 6 months following open and Laparoscopic TME [32]. In our study, after 6 months the abnormal IIEF scores showed dramatic improvement in both groups (40\% in the laparoscopic arm compared to $42.5 \%$ for the open TME arm), with no statistical difference ( $p$ value $<0.876$ ). Analysis of SD in relation to age group demonstrated a significant difference $(\mathrm{p}<0.05)$ in favor of laparoscopic approach for patients younger than 30 years $(16.7 \%$ vs. $40 \%)$ at 6 months postoperatively. In a comparative study between the two approaches, it was demonstrated that the impotency rates were higher after open surgery, with SD rate of $29 \%$ in the open group, compared to 5\% in the laparoscopic group [33]. Another study demonstrated the opposite finding, with a higher rate of postoperative SD for laparoscopic TME with $41 \%$ experiencing SD compared with only $4.5 \%$ in the open group [34].

Laparoscopic TME has many advantages over open TME in the preservation of the pelvic nerves. The magnified view and improved visualization of deep pelvic structures facilitate the identification and preservation of pelvic autonomic nerves. Meanwhile, the 30-degree laparoscope lens can reach the narrow lesser pelvis, breaking through the blind zone, otherwise encountered during open procedures [34]. These advantages may be particularly important when operating in a deep narrow pelvis [35]. However, the technical demands and the extensive use of high energy sources and rigid instruments in traction and dissection may predispose to higher rates of nerve injuries and consequently, a higher rate of male SD reported in different published series after laparoscopic TME.

Focusing on patients with low-lying rectal cancers undergoing sphincter-preserving operations, one study demonstrated that laparoscopic TME patients had better sexual functions and fewer male sexual problems $12-18$ months postoperatively, and better sexual enjoyment than open TME patients. The improvement in the total IIEF score, from 3 to 6 months postoperatively, may be related to healed neuropraxia of the pelvic nerves, as well as to the improvement in the psychological state and body shape, as well as recovery from side effects of chemotherapy and radiotherapy. It has been postulated that impotence failing to improve within 3 - 6 months after surgery should be accepted 
as permanent [36] [37]. However, at least 15 months have been supported as the reasonable waiting period before final conclusions should be made with regard to sexual function. At 15 months postoperatively, the late side effects of adjuvant chemotherapy and radiotherapy, as well as the natural restoration of both psychological and surgical factors, reach their plateau [21]. Pelvic radiation therapy itself may affect sexuality, but its role has not been clearly proven, as several studies were not able to prove the adverse effect of radiation therapy on SD [27] [31].

One study showed that stoma patients seem to have the consistently lower quality of life since colostomy can contribute to a negative body image and result in a reluctance to engage in sexual activity [38]. Although it is supported that less sexual dysfunction accompanies laparoscopic TME, our study does not support this.

Our study had a rather limited number of patients. However, since the superiority or inferiority of the laparoscopic vs. open approaches, in terms of sexual dysfunction, continues to exist, studies like ours, even if referring to small groups of patients, remain valuable. Our study maintains its value from the systematic approach adopted, using fixed assessment points, and objective tool for the periodic postoperative measurement of sexual dysfunction.

\section{Conclusion}

In this randomized prospective study, there was no significant difference between the laparoscopic and open TME, when IIEF scores preoperatively, at 3 and at 6 months postoperatively were compared. Since age at presentation is an independent risk factor, this study also demonstrates a significant difference in IIEF score ( $p$ value $<0.05$ ) in favor of the laparoscopic TME over the open TME, at 6 months postoperatively, for patients younger than 30. These findings add to the favorable outcome of laparoscopic TME with regards to postoperative complications, postoperative pain, hospital stay, the return of bowel functions and cosmetic results, compared to open TME.

\section{Conflicts of Interest}

The authors declare no conflicts of interest regarding the publication of this paper.

\section{References}

[1] Curado, M.P., Edwards, B., Storm, H., Ferlay, J., Heanue, M. and Boyle, P. (2007) Cancer Incidence in Five Continents. IARC Scientific, 9.

[2] O’Connell, J.B., Maggard, M.A. and Ko, C.Y. (2004) Colon Cancer Survival Rates with the New American Joint Committee on Cancer Sixth Edition Staging. Journal of the National Cancer Institute, 96, 1420-1425.

[3] Soliman, A.S., Bondy, M.L., El-Badawy, S.A., Mokhtar, N., Eissa, S., Bayoumy, S., Seifeldin, I.A., Houlihan, P.S., Lukish, J.R., Watanabe, T., Chan, A.O., Zhu, D., 
Amos, C.I., Levin, B. and Hamilton, S.R. (2001) Contrasting Molecular Pathology of Colorectal Carcinoma in Egyptian and Western Patients. British Journal of Cancer, 85, 1037-1046. https://doi.org/10.1054/bjoc.2001.1838

[4] Heald, R.J. and Ryall, R. (1982) The Mesorectum in Rectal Cancer Surgery-The Clue to Pelvic Recurrence? British Journal of Surgery, 69, 613-616.

https://doi.org/10.1002/bjs.1800691019

[5] Kinn, A.C. and Ohman, U. (1986) Bladder and Sexual Function after Surgery for Rectal Cancer. Diseases of the Colon \& Rectum, 2943-2948. https://doi.org/10.1007/BF02555287

[6] Heald, R.J., Moran, B.J., Ryall, R.D., Sexton, R. and MacFarlane, J.K. (1998) Rectal Cancer: The Basing Stroke Experience of Total Mesorectal Excision, 1978-1997. The Archives of Surgery, 133, 894-899. https://doi.org/10.1001/archsurg.133.8.894

[7] Rosen, R.C., Riley, A., Wagner, G., Osterloh, I.H., Kirkpatrick, J. and Mishra, A. (1997) The International Index of Erectile Functions (IIEF): A Multidimensional Scale of Assessment of Erectile Dysfunction. Urology, 49, 822-830. https://doi.org/10.1016/S0090-4295(97)00238-0

[8] Sterk, P., Shekarriz, B., Günter, S., Nolde, J., Keller, R., Bruch, H.P. and Shekarriz, H. (2005) Voiding and Sexual Dysfunction after Deep Rectal Resection and Total Mesorectal Excision. International Journal of Colorectal Disease, 20, 423-427. https://doi.org/10.1007/s00384-004-0711-4

[9] Varpe, P., Huhtinen, H., Rantala, A., Salminen, P., Rautava, P., Hurme, S. and Grönroos, J. (2011) Quality of Life after Surgery for Rectal Cancer with Special Reference to Pelvic Floor Dysfunction. Colorectal Disease, 13, 399-405.

https://doi.org/10.1111/j.1463-1318.2009.02165.x

[10] Zugor, V., Miskovic, I., Lausen, B., Matzel, K., Hohenberger, W., Schreiber, M., Labanaris, A., Neuhuber, W., Witt, J. and Schott, G.E. (2010) Sexual Dysfunction after Rectal Surgery: A Retrospective Study of Men without Disease Recurrence. The Journal of Sexual Medicine, 7, 3199-31205. https://doi.org/10.1111/j.1743-6109.2010.01846.x

[11] Swallow, C.J., McRae, H.M., Gryfe, R. and Mc Lead, R. (2005) Prevalence of Male and Female Sexual Dysfunctions High Following Surgery for Rectal Cancer. Annals of Surgery, 242, 212-223. https://doi.org/10.1097/01.sla.0000171299.43954.ce

[12] Nesbakken, A., Nygaard, K., Bull-Njaa, T., Carlsen, E. and Eri, L.M. (2000) Bladder and Sexual Dysfunction after Mesorectal Excision for Rectal Cancer. British Journal of Surgery, 87, 206-210. https://doi.org/10.1046/j.1365-2168.2000.01357.x

[13] Tekkis, P.P., Cornish, J.A., Remzi, F.H., Tilney, H.S., Strong, S.A., Church, J.M., Lavery, I.C. and Fazio, V.W. (2009) Measuring Sexual and Urinary Outcomes in Women after Rectal Cancer Excision. Diseases of the Colon \& Rectum, 52, 46-54. https://doi.org/10.1007/DCR.0b013e318197551e

[14] Junginger, T., Kneist, W. and Heintz, A. (2003) Influence of Identification and Preservation of Pelvic Autonomic Nerves in Rectal Cancer Surgery on Bladder Dysfunction after Total Mesorectal Excision. Diseases of the Colon \& Rectum, 46, 621-628. https://doi.org/10.1007/s10350-004-6621-2

[15] Shirouzu, K., Ogata, Y. and Araki, Y. (2004) Oncologic and Functional Results of Total Mesorectal Excision and Autonomic Nerve-Preserving Operation for Advanced Lower Rectal Cancer. Diseases of the Colon \& Rectum, 47, 1442-1447. https://doi.org/10.1007/s10350-004-0618-8

[16] Kim, N.K., Aahn, T.W., Park, J.K., Lee, K.Y., Lee, W.H., Sohn, S.K. and Min, J.S. (2002) Assessment of Sexual and Voiding Function after Total Mesorectal Excision 
with Pelvic Autonomic Nerve Preservation in Males with Rectal Cancer. Diseases of the Colon \& Rectum, 45, 1178-1185. https://doi.org/10.1007/s10350-004-6388-5

[17] Kneist, W. and Junginger, T. (2007) Male Urogenital Function after Confirmed Nerve Sparing Total Mesorectal Excision with Dissection in Front of Denonvillier's Fascia. World Journal of Surgery, 31, 1321-1328.

https://doi.org/10.1007/s00268-007-9008-4

[18] Maas, C.P., Moriya, Y., Steup, W.H., Kiebert, G.M., Kranenberg, W.M.K. and van de Velde C.J.H. (1998) Radical and Nerve-Preserving Surgery for Rectal Cancer in the Netherlands: A Prospective Study on Morbidity and Functional Outcome. British Journal of Surgery, 85, 92-97.

[19] Breukink, S.O., Van Driel, M.F., Pierie, J.P., Dobbins, C., Wiggers, T. and Meigerink, W.J. (2008) Male Sexual Function and Lower Urinary Tract Sumptomes after Laparoscopic Total Mesorectal Excision. International Journal of Colorectal Disease, 23, 1199-1205. https://doi.org/10.1007/s00384-008-0547-4

[20] Hasan, E.B., Enaba, M., ElKassas, G., El-Alkali, F. and Elfert, A.A. (2011) Indications and Outcome of Colonoscopy in the Middle of Nile Delta in Egypt. Digestive Diseases and Sciences, 56, 2120-2123. https://doi.org/10.1007/s10620-010-1538-1

[21] Abou-Zeid, A.A., Khafagy, W., Marzouk, D.M., Ala, A., Mostafa, I. and Ela, M.A. (2002) Colorectal Cancer in Egypt. Diseases of the Colon \& Rectum, 45, 1255-1260. https://doi.org/10.1007/s10350-004-6401-Z

[22] Al-Barrak, J. and Gill, S. (2011) Presentation and Outcomes of Patient Aged 30 Years and Younger with Colorectal Cancer: A 20-Year Retrospective Review. Medical Oncology, 28, 1058-1061. https://doi.org/10.1007/s12032-010-9639-4

[23] Rodriguez, M.A., Mahoney, M.C., Peterilli, N.J. and Weber, T.K. (1996) Colorectal Cancer in Patients Aged 30 Years or Younger. Surgical Oncology, 5, 189-194. https://doi.org/10.1016/S0960-7404(96)80043-0

[24] Adolf, M., Arnaud, J.P., Shloegel, M., Thiabaud, D. and Bergarmaschi, R. (1989) Colorectal Cancer in Patients under 40 Years Age. Diseases of the Colon \& Rectum, 29, 322-3252. https://doi.org/10.1007/BF02554121

[25] Hendren, S.K., O’Connor, B.I., Liu, M., Asano, T., Cohenn, Z., Swallow, C.J., Macrae, H.M., Gryfe, R. and McLeod, R.S. (2005) Prevalence of Male and Female Sexual Dysfunction Is High Following Surgery for Rectal Cancer. Annals of Surgery, 242, 212-223. https://doi.org/10.1097/01.sla.0000171299.43954.ce

[26] Guillou, P.J., Quirke, P., Thorpe, H., Walker, J., Jayne, D.G., Smith, A.M., Health, R.M. and Brown, J.M. (2005) Short-Term Endpoints of Conventional versus Laparoscopic-Assisted Surgery in Patients with Colorectal Cancer (MRC CLASICC Trial): Multicenter, Randomized Controlled Trial. The Lancet, 365, 1718-1726. https://doi.org/10.1016/S0140-6736(05)66545-2

[27] Ally, E.H. (2009) Laparoscopic Colorectal Surgery: Summary of the Current Evidence. Annals of the Royal College of Surgeons of England, 91, 541-544. https://doi.org/10.1308/003588409X464757

[28] Aly, E.H. (2012) Laparoscopic Surgery for Rectal Cancer: Approaches, Challenges and Outcome. In: Contemporary Issues in Colorectal Surgical Practice, IntechOpen, London, 57.

[29] Jayne, D.G., Brown, J.M., Thorpe, H., Walker, J., Quirke, P. and Guillou, P.J. (2005) Bladder and Sexual Functions Following Resection for Rectal Cancer in Randomized Clinical Trial of Laparoscopic versus Open Technique. British Journal of Surgery, 92, 1124-1132. https://doi.org/10.1002/bjs.4989 
[30] Good, D.W., O’Riordan, J.M., Moran, D., Keane, F.B., Eguare, E., O’Riordain, D.S. and Neary, P.C. (2011) Laparoscopic Surgery for Rectal Cancer: A Single-Center Experience of 120 Cases. International Journal of Colorectal Disease, 26, 1309-1315. https://doi.org/10.1007/s00384-011-1261-1

[31] Andersson, J., Angenete, E., Gellerstedt, M., Angerås, U., Jess, P., Rosenberg, J., Fürst, A., Bonjer, J. and Haglind, E. (2013) Health-Related Quality of Life after Laparoscopic and Open Surgery for Rectal Cancer in a Randomized Trial. British Journal of Surgery, 100, 941-949. https://doi.org/10.1002/bjs.9144

[32] Stamopoulos, P., Theodoropoulos, G.E., papailiou, J., Savidis, D., Bramis, K., Panoussopoulos, S.G. and Leandros, E. (2009) Prospective Evaluation of Sexual Function after Open and Laparoscopic Surgery for Rectal Cancer. Surgical Endoscopy, 23, 2665-2674. https://doi.org/10.1007/s00464-009-0507-2

[33] Asoglu, O., Matlim, T., Karanlik, H., Atar, M., Muslumanoglu, M., Kapran, Y., Igci, A., Ozmen, V., Kecer, M. and Parlak, M. (2009) Impact of Laparoscopic Surgery on Bladder and Sexual Functions after Total Mesorectal Excision for Rectal Cancer. Surgical Endoscopy, 23, 296-303. https://doi.org/10.1007/s00464-008-9870-7

[34] Quah, H.M., Jayne, D.G., Eu, K.W. and Seow-Choen, F. (2002) Bladder and Sexual Dysfunction Following Laparoscopically Assisted and Conventional Open Mesorectal Resection for Cancer. British Journal of Surgery, 89, 1551-1556. https://doi.org/10.1046/j.1365-2168.2002.02275.x

[35] Leroy, J., Jamali, F., Forbes, L., Smith, M., Rubino, F., Mutter, D. and Marescaux, J. (2004) Laparoscopic Total Mesorectal Excision (TME) for Rectal Cancer Surgery: Long Term Outcomes. Surgical Endoscopy and Other Interventional Techniques, 18, 281-289. https://doi.org/10.1007/s00464-002-8877-8

[36] Yang, L., Yu, Y.Y., Zhou, Z.G., Li, Y., Cu, B., Song, J.M., Liu, H.Y. and Jiang, X. (2007) Quality-of-Life Outcomes Following Laparoscopic Total Mesorectal Excision for Low Rectal Cancers: A Clinical Controlled Study. European Journal of Surgical Oncology, 33, 575-5792. https://doi.org/10.1016/j.ejso.2006.11.026

[37] Moriya, Y., Hojo, K., Sawada, T. and Koyama, Y. (1989) Significance of Lateral Node Dissection for Advanced Rectal Carcinoma at or Below the Peritoneal Reflection. Diseases of the Colon \& Rectum, 32, 307-315. https://doi.org/10.1007/BF02553486

[38] Engel, J., Keer, J., Schlesinger-Raab, A., Eckel, R., Sauer, H. and Holzel, D. (2003) Quality of Life in Rectal Cancer Patients: A Four-Year Prospective Study. Annals of Surgery, 238, 203-2013. https://doi.org/10.1097/01.sla.0000080823.38569.b0 